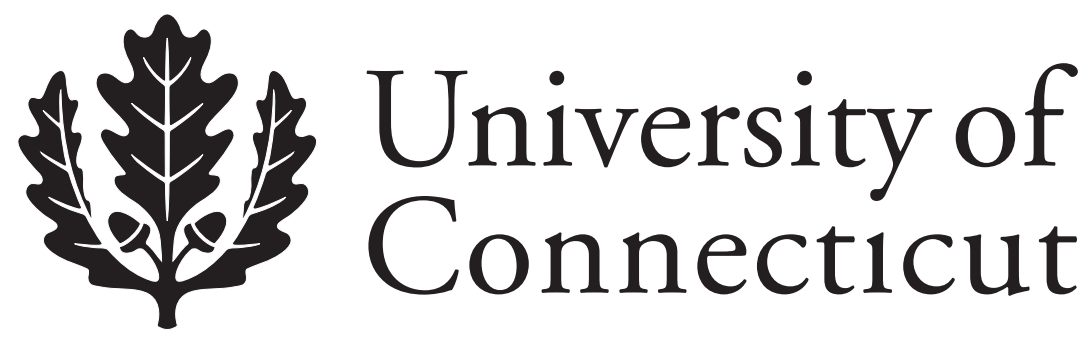

Department of Economics Working Paper Series

\title{
A Question of Title: Property Rights and Asset Values
}

Thomas J. Miceli

University of Connecticut

Henry J. Munneke

University of Georgia

C. F. Sirmans

Florida State University

Geoffrey K. Turnbull

Georgia State University

Working Paper 2008-32

August 2008

341 Mansfield Road, Unit 1063

Storrs, CT 06269-1063

Phone: (860) 486-3022

Fax: (860) 486-4463

http://www.econ.uconn.edu/

This working paper is indexed on RePEc, http://repec.org/ 


\begin{abstract}
This paper examines the impact of land title systems on property values. The predominant system in the U.S., the recording system, awards title to claimants over current possessors, whereas the Torrens registration system awards title to the current owner. In theory, the registration system maximizes property value, all else equal, but in practice, the systems differ depending on the risk of a claim and administrative costs. A natural experiment in Cook County, Illinois, where both systems have existed since 1897, allows a test of the theory. The results, based on commercial and industrial properties, reveal that parcels tend to self-select into the two systems based on the predictions of the theory.
\end{abstract}

Journal of Economic Literature Classification: K11, P14, R14

Keywords: Land title system, property rights, recording system, Torrens system 


\section{A Question of Title: Property Rights and Asset Values}

\section{Introduction}

Well-defined private property rights are fundamental to market efficiency. As important, though often overlooked as an arcane detail by economists, is the question of title-the rule used to identify the superior ownership claim from among competing legitimate claims to an asset. DeSoto (2000) argues that a title system, regardless of the specific ownership rule it maintains, is an essential feature for efficient integration of capital and land markets in developing countries. At the same time, Miceli, Sirmans, and Turnbull (1998, 2000) show that the specific characteristics of the title system can affect both the pace of urban development and the pattern of investment in real estate assets, even in developed countries.

The theoretical analysis to date focuses on how title system characteristics affect land development decisions and land values. This paper extends the analysis to developed real estate assets, offering a stylized model showing how differences in title system characteristics affect values of different types of assets. Cook County, Illinois, offers a natural experiment wellsuited to empirical tests of the value relationships predicted by the theory. Uniquely, from 1897 to 1996 , Cook County operated two alternative title systems at the same time, allowing real estate owners to select the title system for their property. This study uses Cook County transactions data to test the implications of the theory for relative asset values across the two types of title systems.

While the focus here is on commercial and industrial real estate, the question of title is a general concern. Ownership risk from competing claims arises for durable assets because of imperfect records arising from theft or fraud, errors made in good faith, the high cost of verification, or incomplete or lost records. In general, there are three systems for resolving 
conflicting ownership claims: possession, recording, and registration. The possession rule generally requires physical possession of the asset to establish a superior claim to ownership. Baird and Jackson (1984) offer the example of Twyne's Case from 1601, in which the seller of a herd of sheep continued to take care of the herd after its sale to a second party. The English court interpreted the uninterrupted possession as evidence that ownership had not changed hands. A form of the possession rule survives to this day in common law countries in the form of adverse possession for real estate, where a previously established owner can lose title by failing to retain possession (Baker, et al., 2001).

The recording system (also known as the American rule in the real estate context) awards ownership of an asset to the individual with the earlier claim. This is the rule with which most individuals are probably familiar in the U.S. For example, vehicle ownership goes to the individual with the prior legitimate claim as revealed by an examination of (public) records. Later claims arising subsequent to acquisition by theft, fraud, or error typically are not honored, even when subsequent purchasers acted in good faith. Similarly, provenance in artwork, old wines, or collectibles relies on (private) records to verify the chain of ownership (although, in these cases it is as much to verify or reinforce the claim of authenticity as much as clear title).

The registration system, on the other hand, awards ownership to the individual with the most recent claim. ${ }^{1}$ The English rule of the law merchant awards ownership of an asset to the merchant acquiring it in good faith, even if purchased from a thief; the Uniform Commercial

1 The Torrens title system is a version of the real estate registration system that includes a method for compensating rejected legitimate claimants for the value of their lost claim. See Shick and Plotkin (1978) and Miceli, Sirmans, and Turnbull (1998, 2000) for further details. Not all registration systems incorporate this explicit insurance feature. 
Code applies a similar doctrine for negotiable instruments in the U.S. (Baird and Jackson, 1984, p. 300).

Real estate presents an interesting class of assets when it comes to title systems. Both the recording and registration title systems currently are used to resolve ownership questions for real estate assets, depending on the locale (Shick and Plotkin, 1978). Scotland and most of the U.S. rely on the recording title system, while England, most Commonwealth countries, many Civil Law countries, and Hawaii and parts of Illinois, Massachusetts, and Minnesota in the U.S. use or have used the registration title system. Therefore, questions about how title system characteristics affect asset markets are particularly relevant for real estate assets.

Our model focuses on the differences between archetypical registration and recording systems. The registration system assigns the current property holder title in the event that a competing claim arises. This rule minimizes ownership risk for the current holder as well as a new purchaser. Registration, however, requires an affirmative action by a magistrate or land court to consummate a transaction, thereby increasing transactions costs. In contrast, the recording system awards title to the claimant over the current holder. This rule imposes greater ownership risk on current holders or new purchasers. ${ }^{2}$ At the same time, though, the transaction can be completed without the intercession of a magistrate or similar official action, and so results in lower transactions costs. The relative advantage of one title system over the other reflects the relative ownership risk and transaction cost effects on value and therefore varies by property type.

The remainder of the paper is organized as follows. Section 2 presents a stylized model of the two title systems. The theory predicts that asset values vary across title systems so that,

\footnotetext{
${ }^{2}$ This risk is due to past errors or fraud in determining title. The risk is reduced, but not eliminated, by title searches, which are conducted with each sale of the property (Baker, et al., 2002).
} 
when offered the choice of systems (as in Cook County), asset values include an endogenous title selection effect. Section 3 explains the selection correction model for asset values in this application. Sections 4 and 5 describe the data and report the empirical results, respectively. Section 6 concludes.

\section{Theory}

The two property title systems we consider, the recording system and the registration (or Torrens) system, differ in the following way. ${ }^{3}$ Under the recording system, if a successful claim is made, the claimant receives title to the property but must compensate the current owner for the value of any improvements put in place subsequently. Most landowners purchase private title insurance to protect them against such claims. ${ }^{4}$ In contrast, under the Torrens registration system examined here, if a claim is made, the current owner retains title, but the claimant is entitled to monetary compensation for the value of the lost asset, to be paid from a fund that is financed by fees assessed on those owners who register their property (a form of public insurance). The fundamental difference between the two systems, then, is whether the current owner or the claimant receives title to the land in the event of a valid competing claim.

The question of interest here is whether one of these systems results in a higher property value, holding all other factors constant. We consider only developed land since all properties in our sample are developed, either for commercial or industrial use. ${ }^{5}$ Let $V_{i}$ be the observed market value of a property under title system $i$, where $i=r e c, r e g$ (recording or registration system, respectively) which consists of the present value of the returns from the property, $R$,

\footnotetext{
${ }^{3}$ For a more detailed analysis of the investment incentives effects of the two systems on which the model in this section is based, see Miceli, Sirmans, and Turnbull (1998, 2000).

${ }^{4}$ Mortgage companies typically require borrowers to purchase title insurance for at least the amount of the mortgage (Miceli and Sirmans, 1997).

${ }^{5}$ Miceli, Munneke, Sirmans, and Turnbull (2002) consider the case of undeveloped land.
} 
less the present value of the expected transaction costs arising from future transfers of the property under system $i, T_{i}$, and the insurance premium (or registration fee), $\pi_{i}$, which reflects the title risk. Thus,

$$
V_{i}=R-T_{i}-\pi_{i}
$$

Since the title systems require compensation for either the value of improvements or the value of the undeveloped land, we will need to decompose the total market value as follows:

$$
V_{i}=P_{i}+I
$$

where $P_{i}$ is the value of the land under system $i$, and $I$ is the value of the capital improvements.

Note that (1) and (2) imply

$$
P_{i}=R-I-T_{i}-\pi_{i}
$$

which reflects a competitive land market. Also note that the gross returns from the property, $R$, and the value of improvements, $I$, are treated as being independent of the title system (i.e., they are not subscripted by $i$ ). This reflects the fact that, given full and fair insurance against a title claim under both systems, the amount of capital owners of undeveloped land will invest in their land will be independent of the title system, and will be efficient. ${ }^{6}$

Consider next the determination of $\pi_{i}$ under the two systems. First, under the recording system, recall that if a claim is made, the current owner loses title but is reimbursed for the cost of the improvements, $I$. Thus, his net loss is $R-T_{\text {rec }}-I$. Letting $\theta$ be the probability of a successful claim (which we assume is independent of the title system), and assuming an actuarially fair premium, we obtain

$$
\pi_{r e c}=\theta\left(R-T_{r e c}-I\right) .
$$

\footnotetext{
${ }^{6}$ Specifically, once a buyer has purchased a parcel of undeveloped land for $P_{i}$, he will choose $I$ to maximize $R(I)-$ $I-T_{i}-\pi_{i}$, where $R(I)$ is the gross return written as a function of $I$. Assuming that the owner treats $T_{i}$ and $\pi_{i}$ as fixed, his optimal choice of $I$ will solve $R^{\prime}=1$, which is efficient and independent of the title system (Miceli, Sirmans, and Turnbull, 1998). Note that there is no moral hazard problem here, despite full insurance, because the investment in the land is not lost in the event of a claim even when possession changes.
} 
Substituting this into (1) and rearranging yields

$$
V_{\text {rec }}=(1-\theta)\left(R-T_{\text {rec }}\right)+\theta I .
$$

In contrast, under the registration system, the current owner retains title but must reimburse a successful claimant (typically, through the public fund) for the value of the undeveloped land. Thus,

$$
\pi_{\text {reg }}=\theta P_{\text {reg }} .
$$

Substituting this expression into (3) and solving for $P_{\text {reg }}$ yields

$$
P_{\text {reg }}=\frac{1}{1+\theta}\left(R-I-T_{\text {reg }}\right) .
$$

Finally, substituting (7) into (2) and rearranging yields

$$
V_{\text {reg }}=\frac{1}{1+\theta}\left(R-T_{\text {reg }}+\theta I\right) .
$$

A current property holder prefers the title system that maximizes the market value of his property. Suppose first that the transaction costs are the same under the two systems-that is, $T_{r e c}=T_{r e g}=T$. In this case we obtain from (5) and (8)

$$
V_{\text {reg }}-V_{\text {rec }}=\frac{\theta^{2}}{1+\theta}(R-I-T),
$$

which is positive given $R-I-T>0$. Thus, the registration system yields the higher property value, all else equal. The intuitive explanation is as follows. Under the registration system, the cost of a claim to the current holder is the value of the land. Thus, the existence of title risk reduces land value like a property tax. In contrast, under the recording system, the cost of a claim to the current holder is the lost future income stream. In this case, title risk acts like an income tax on land earnings. And since a given percentage income tax reduces value more than the same percentage property tax, the cost of a claim is higher under the recording system. 
Now suppose that transaction costs under the two systems differ. This is important in practice because the available evidence suggests that the cost of transferring a registered property in Cook County is considerably higher than for comparable properties under the recording system. The difference reflects understaffing and other bureaucratic impediments associated with use of the registration system (Shick and Plotkin, 1978, pp. 139-142). Thus, it seems likely that, at least for our sample of properties, $T_{r e g}>T_{\text {rec }}$. This obviously gives an advantage to the recording system, all else equal. In the extreme case where there is no risk (i.e., $\theta=0$ ), both (5) and (8) become

$$
V_{i}=R-T_{i}
$$

In a risk-free world, all landowners would prefer the recording system so as to minimize transaction costs. At the other extreme, if $\theta=1$,

$$
V_{r e g}-V_{r e c}=\frac{1}{2}\left(R-I-T_{r e g}\right),
$$

which again is positive. Thus, when the risk of a claim is very high, the registration system is preferred despite the higher transaction costs. ${ }^{7}$ Now observe that the asset value $V_{i}$ is decreasing in $\theta$ under both systems. It must therefore be the case that there is critical value of $\theta$, denoted $\theta^{*}$, such that the recording system is preferred for $\theta<\theta^{*}$ (low risk properties) whereas the registration system is preferred for $\theta>\theta^{*}$ (high risk properties). Since $\theta$ varies by property, this self-selection effect can be shown graphically as in Figure 1: $V_{\text {rec }}$ lies above $V_{\text {reg }}$ for properties for which $\theta<\theta^{*}$ and below for properties for which $\theta>\theta^{*}$.

\footnotetext{
${ }^{7}$ This is consistent with the fact that Torrens was first introduced in Cook County in the aftermath of the Great Chicago Fire to deal with the loss of official land records (Shick and Plotkin, 1978, p. 139).
} 


\section{Empirical Model}

The theoretical model implies that, when given a choice, property owners will find it beneficial to register their property under the Torrens registration system when the title risk for the property is high, while others will find the recording system beneficial when the title risk for the property is low. Thus, the relative value under the two alternative title systems should play a role in an individual's choice of title system. The total market value of an improved property under the registration system can be written as:

$$
V_{1 i}=\alpha_{1}+\beta_{1}^{\prime} X_{1 i}+u_{1 i}
$$

while the total market value of an improved property under the recording system can be written as:

$$
V_{0 i}=\alpha_{0}+\beta_{0}^{\prime} X_{0 i}+u_{0 i}
$$

where $V_{s i}$ is the natural logarithm of the $i$ th property's selling price, and $X_{s i}$ represent vectors of property and location characteristics under title system $s$. The individual's choice of title system depends on the relative benefit of each title system choice $\left(V_{1 i}-V_{0 i}\right)$. Although the relative benefit is not directly observable, the title system choice is observed upon the sale of the property. Thus, the underlying choice or selectivity model is:

$$
\begin{aligned}
& I_{i}^{*}=\gamma\left(V_{1 i}-V_{0 i}\right)+\theta y_{i}-\eta_{i} \\
& I_{i}^{*}=\gamma\left(\alpha_{1}+\beta_{1} X_{1 i}-\alpha_{0}-\beta_{0} X_{0 i}\right)-\left(\eta_{i}+\gamma\left(u_{0 i}-u_{1 i}\right)\right) \\
& I_{i}^{*}=\omega^{\prime} Z_{i}-\eta_{i}^{*}
\end{aligned}
$$

where $I_{i}^{*}$ is the underlying response variable $\left(I=1\right.$ if $I_{i}^{*}>0$, otherwise $\left.I=0\right)$; $\omega$ is a vector of parameters to be estimated; and $Z_{i}$ is a vector of regressors that determine the choice of title 
system (those found in the value equations $\left(X_{s i}\right)$, as well as other factors that may determine the choice of title system $\left.\left(y_{i}\right)\right)$; and $\eta_{i}^{*} \sim N\left(0, \sigma^{2}\right)$. Note that the error term of the choice equation contains the errors from the total value equations, indicating selection bias. Thus, in modeling the total value, one must account for the non-random selection process underlying the choice of a title system; failing to do so would lead to biased estimates of the total value parameters. In other words, $\mathrm{E}\left(u_{s i} \mid I=s\right)$ may not equal zero.

To properly analyze the impact of the title system on total value, the empirical model must be constructed in a manner that treats title system choice as endogenous and also recognizes the potential for selection bias. In addition, the model must take into account that total value is not jointly observable under each of the title systems. The total value equation must be estimated conditional on the sample to which it belongs. The conditional expectation of the total value equations can be written as:

$$
E\left(V_{1 i} \mid I=1\right)=\alpha_{1}+\beta_{1} X_{1 i}-\sigma_{1 \eta}\left[\frac{\phi\left(\omega Z_{i}\right)}{\Phi\left(\omega Z_{i}\right)}\right]
$$

and

$$
E\left(V_{0 i} \mid I=0\right)=\alpha_{0}+\beta_{0} X_{0 i}+\sigma_{0 \eta}\left[\frac{\phi\left(\omega Z_{i}\right)}{1-\Phi\left(\omega Z_{i}\right)}\right]
$$

where $\phi$ is the standard normal probability density function, and $\Phi$ is the standard normal distribution function. Note that $\sigma_{s \eta}$ measures the covariance between the error term in regime $s$ and the error term of the choice function. The significance of the parameter on $\sigma_{s \eta}$ is a test for selection bias. If this covariance differs from zero, selection bias is indicated. Estimating the conditional expectation of the total value equations over the appropriate subsample provides consistent estimates of $\beta_{s}$, but does not lead to a direct measure of the impact of title systems. 
Lee, et al. (1979) provides a general framework for estimating a switching regression model with endogenous switching. ${ }^{8}$ This approach is based on the estimation of an unconditional expected total value equation. In addition to allowing the model to be estimated with an endogenous regime choice, it also provides a direct measure of the impact of the title system choice. The unconditional expected total value equation is:

$$
E\left(V_{i}\right)=E\left(V_{1 i} \mid I_{i}=1\right) \Phi_{1}+E\left(V_{0 i} \mid I_{i}=0\right) \Phi_{0}
$$

where $V_{i}$ is the natural logarithm of the selling price of the $i$ th property, and $\Phi_{s}$ is the probability of choosing title system $s$.

The theoretical model focuses on property value differences from the title systems that arise from title risk and transactions cost differences. Therefore, we assume identical location and physical characteristics on value across title system regimes, so that title system differences show up as differences in intercepts. Substituting equations (16) and (17) into (18), constraining the slope parameters to be constant across title system equations and using $X_{1 i}=$ $X_{0 i}=X_{i}$ yields the estimable asset value model

$$
V_{i}=\alpha_{0}+\beta X_{i}+\left(\alpha_{1}-\alpha_{0}\right) \Phi_{i}+\left(\sigma_{0 \eta}-\sigma_{1 \eta}\right) \phi_{i}+\lambda_{i}
$$

The estimated coefficient on $\Phi$ provides a direct measure of the impact of the title system (i.e., the difference in intercepts). The parameter attached to $\varphi$ provides insight into the selection process.

In addition to a direct measure of the impact of title systems, this endogenous dummy variable approach also provides insight into the selection process. The theoretical argument indicates that a property in the registration system should have a higher value in that system than under the recording system. Note that it does not indicate a relationship between the

\footnotetext{
${ }^{8}$ Heckman (1976) also considers an endogenous switching model that only allows the constant term to shift across regimes.
} 
absolute magnitude under each title systems (i.e., registered properties need not yield a higher overall value). Although unobservable, the expected total value under the recording system, given that the property is under the registration system, is:

$$
E\left(V_{0 i} \mid I=1\right)=\alpha_{0}+\beta_{0} X_{0}-\sigma_{0 u} \frac{\phi}{\Phi}
$$

while the expected price under the registration system, given that the property is under the recording system, is:

$$
E\left(V_{1 i} \mid I=0\right)=\alpha_{1}+\beta_{1} X_{1}+\sigma_{1 u} \frac{\phi}{1-\Phi}
$$

A comparison of the difference of the expected total value equations within group $s$ (e.g., $\left.E\left(V_{l} \mid I=1\right)-E\left(V_{O} \mid I=1\right)\right)$ provides information on the selection process and whether the choice of title system is made in a manner that yields a higher value.

\section{Data}

The empirical analysis is built upon a unique data set drawn from the property transactions within Cook County, Illinois. Cook County is found in the northeastern corner of the state and fully encompasses the city limits of Chicago. Within this county, two alternative title systems have existed simultaneously from 1897 to 1996 . The Torrens system was introduced to the area in response to the loss of nearly all land records in the Chicago fire of 1871. In addition, the study makes use of transaction level data, not appraised or assessed values.

The sales data were compiled by Experian (formerly TRW-REDI) from the real estate transfer declarations, site visits, and various other documents. Illinois state law requires that real estate transfer declarations be filed with each real estate sale. The sales data provide site 
and improvement characteristics, as well as information on the location of the parcel. ${ }^{9}$ The sales data have been augmented with neighborhood characteristics from a second data source obtained from the Northeastern Illinois Planning Commission (NIPC). The NIPC data were used to identify quarter sections (a one-half mile by one-half mile square) having a high concentration in four particular land uses: railway, roadway, conservation open space, and recreational open space. For example, quarter sections with $20 \%$ of the land area devoted to rail transportation were identified as having a high concentration of rail activity. (Note that in the case of railway actively, it is not possible to distinguish between passenger and freight lines.) The NIPC data were obtained for 1990, under the assumption that land uses (i.e., roads, parks, etc.) as a percentage of a quarter section remained sufficiently constant over the study period. The straight-line distance from each sale to the quarter section identified as containing a high concentration of a particular land use was measured.

Property index numbers, found within the sales data, helped identify if properties were registered using the registration or Torrens system. To test the accuracy of the property index number system, a sample of the Torrens properties were verified using public records from the County's Registrar Office. The data were drawn from two distinct time periods; the calendar years of $1986 \& 1987$ and $1990 \& 1991$. The years between these time periods were omitted due to problems within the data and the high cost of correcting these problems. The time periods used also provide an interesting backdrop in that they represent a time period of normal operation and one a few years prior to the 1996 repeal of the Torrens system within the state.

\footnotetext{
${ }^{9}$ For the purpose of this study, all parcels contained within the data set are assumed to be located at the center of the quarter section, a one half mile square area, in which they are located. This location assumption allows for the easy computation of the straight line distance (in miles) for each sale to particular locations, such as the city center. The center of the central business district is identified as the intersection of Madison and State Streets.
} 
The full sample contains 2,363 transactions of commercial and industrial properties. Commercial (office/retail) properties make up $70 \%$ of the sample. Of the full sample, only 206 , or $8.72 \%$ of the sample, are identified as Torrens properties. Table 1 provides a statistical summary of the full sample and each sub-sample (non-Torrens, Torrens). On average, Torrens properties tend to be located further from the city center. Although the size of the improvements found on a Torrens property is smaller on average than found on non-Torrens property, they tend to be located on relatively larger lots.

\section{Empirical Results}

The first stage estimates the probit model over the full sample of commercial and industrial properties and then uses the probit estimates to estimate the probability of a parcel being a registered using the registration system, as well as to obtain an estimate of the selection variable. The second stage estimates separate commercial and industrial value equations including the endogenous registration variable and the selection variable constructed from the probit estimates.

Table 2 reports the title choice equation estimates. The results indicate that location and timing characteristics play a significant role in the likelihood of a property being in the registration system. Properties sold in the latter time period are more likely to be registered. As the repeal of Cook County's registration system approached, properties were more likely to be registered in that system. Properties located further from the city center, as well as properties located further from concentrations of recreational areas, are also more likely to be registered. As lot size increases, the probability of registering the property decreases. Registration is also more likely as the age of a property increases; this likelihood increases at a decreasing rate. 
Registration system activity by surrounding properties increases the likelihood of a particular property using the registration system, a result consistent with the notion that pervasive title problems are not necessarily isolated in individual properties, but may also reflect underlying neighborhood-wide title problems. Although many of the individual parameters are not statistically significant, we can reject the null hypothesis that all of the parameters are equal to zero at the $5 \%$ level.

The value equation estimates provide some interesting results. The low frequency of registration properties in the sample require that a single probit model be estimated over the entire sample. However, the sample can be split by land use type when estimating the value equations. Table 3 reports the commercial and industrial sample total value equation estimates. Overall, the estimated impact of the physical and site characteristics from the commercial and industrial estimation are consistent with expectations, as well as being consistent between the models. The coefficients on the lot area variables are significantly different from one, indicating that the price per unit of land is not constant with respect to lot size, but declines as lot sizes increase. This type of value concavity is consistent with previous studies of land values. ${ }^{10}$ As expected, total value increases as building area increases. The age of the improvements is found to have a negative effect on total value, but this effect diminishes as the building becomes progressively older. The significance of the parameter on the higher-order variable indicates that a greater degree of flexibility is needed than can be achieved if the firstorder variable is used alone.

The impact of proximity to the city center is consistent across the models, but the local effect of the high concentration of other value factors tends to vary by land use. The value

\footnotetext{
${ }^{10}$ See Brownstone and DeVany (1991), Colwell and Munneke (1997), Colwell and Scheu (1994), Isakson and Ecker (2001), McMillen and McDonald (1989, 1991), and Munneke (1996).
} 
gradient is found to fall with greater distance from the city center, but the gradient is less steep outside of the City of Chicago. The remaining location proximity variables are measured to have a local impact (i.e., are not allowed to distort the entire urban price surface) ${ }^{11}$ For both land uses, total value falls as distance to O'Hare Airport increases. Values for both land uses increase as proximity to rail activity decreases, a result consistent with over allocation of this type of land near rail activity. Commercial land uses are positively impacted by increased proximity to concentrations of open space devoted to conservation and recreation. Price levels are found to be higher in the early 1990's relative to the mid 1980's for both land uses.

The estimates of the endogenous title system and selection variables provide some interesting results. For the commercial land use, the registration system variable coefficient estimate is significantly positive. This result indicates, all else equal, that a property in the registration system will have a higher price than if it were in the recording system. The estimate on the selection variable is not found to be significantly different from zero at a $5 \%$ level. Comparing the difference in equations (16) and (20) and equations (17) and (21) provides insight into the selection process. These differences reveal that registered properties sell for more as registered properties than as recorded properties $\left(E\left(V_{l} \mid I=1\right)>E\left(V_{0} \mid I=1\right)\right)$. This suggests that landowners valued the hybrid registration-recording title system in Cook County, despite the greater transactions costs associated with registration. However, the comparison also indicates that properties in the recording system would sell for more if sold under the registration system $\left(E\left(V_{l} \mid I=0\right)>E\left(V_{0} \mid I=0\right)\right)$. This last result is puzzling; it suggests that

\footnotetext{
${ }^{11}$ Each of these variables is constructed in a manner which measures the local impact on price. As distance from the high concentration increases, the variable increases until the boundary distance is reach. For distances at or greater than the boundary, the price surface is not allowed to be impacted by this land use; the variable has the value of zero. The boundary distance of one mile was found by varying its definition and finding the model of best fit.
} 
property owners in the recording system would have done better to initially register their property in the registration system.

The industrial results also provide interesting insight into the selection process and its impact. The estimate on the registration system variable in the industrial sample is negative and significantly different from zero. While on its own this initially seems like a counterintuitive result, the selection process must be considered. The selection results show that registered properties sell for more as registered properties, as was the case with the commercial land use model. The industrial estimates also indicate that recorded properties sell for more as recorded than as registered properties $\left(E\left(V_{0} \mid I=0\right)>E\left(V_{l} \mid I=0\right)\right)$. These results show that industrial properties are allocated between the title systems in a way that maximizes their value.

Although not reported here, we further divided the commercial and industrial samples into the two study periods, estimating value equations for each of the four subsamples. The results for the selection and registration system variables were virtually unchanged, with the exception that the estimate coefficient of the industrial registered property variable in the early period loses significance.

\section{Conclusions}

The title system represents the rule used to weigh competing claims to ownership of an asset and, as such, is essential for implementing private property rights. This paper analyzed two archetypical systems, registration and recording, offering a stylized model showing how differences in title system characteristics affect values of different types of real estate assets. The registration system minimizes ownership risk for the current holder but typically entails

higher transactions costs. In contrast, the recording system imposes greater ownership risk on current holders but results in lower transactions costs. The relative advantage of one title 
system over the other reflects the relative ownership risk and transaction cost effects on value and therefore varies by property type and land parcel.

We used commercial and industrial property transaction data from Cook County, Illinois, to test this fundamental prediction of the theoretical model in a unique setting in which both registration and recording systems operated side-by-side. The empirical results reveal that properties tend to sort systematically into the two title systems, generally following a selfselection process consistent with the theory. 


\section{References}

Baird, D., and T. Jackson (1984) "Information, Uncertainty, and the Transfer of Property," Journal of Legal Studies, 13, 299-320.

Baker, M., T. J. Miceli, C. F. Sirmans, and G. K. Turnbull (2002) “Optimal Title Search,” Journal of Legal Studies, 31, 139-158.

Baker, M., T. J. Miceli, C. F. Sirmans, and G. K. Turnbull (2001) "Property Rights by Squatting: Land Ownership Risk and Adverse Possession Statutes," Land Economics, 77, 360370.

Brownstone, D. and A. DeVany (1991) "Zoning, Returns to Scale, and the Value of Undeveloped Land," Review of Economics and Statistics 63, 699-704.

Colwell, P., and H. J. Munneke (1997) "The Structure of Urban Land Prices," Journal of Urban Economics, 41, 321-336.

Colwell, P. F. and T. Scheu (1994) "A History of Site Valuation Rules," Journal of Real Estate Research 9, 353-68.

De Soto, H. (2000) The Mystery of Capital: Why Capitalism Triumphs in the West and Fails Everywhere Else, New York: Basic Books.

Heckman, J. J. (1976) "Simultaneous Equations Models with Continuous and Discrete Endogenous Variables and Structural Shifts," In Goldfeld and Quandt (Eds), Studies in NonLinear Estimation, Cambridge, Mass: Ballanger Publishing.

Isakson, H.R. and M.D. Ecker (2001) "An Analysis of the Influence of Location in the Market for Undeveloped Urban Fringe Land," Land Economics 77, 30-41.

Lee L.F., G.S. Maddala, and R.P. Trost (1980) "Asymptotic Covariance Matrices of Two-Stage Probit and Two-Stage Tobit Methods for Simultaneous Equations Models with Selectivity." Econometrica, 48, 491-503.

Lee L.F., G.S. Maddala, and R.P. Trost (1979) “Testing for Structural Change by D-Methods in Switching Simultaneous Equation Models." Proceedings of the American Statistical Association (Business and Economics Section), 461-466.

Maddala, G. S. (1983) Limited-dependent and Qualitative Variables in Econometrics, Cambridge, Mass: Cambridge University Press.

McMillen, D.P., and J.F. McDonald (1989) "Selectivity in Urban Land Value Functions." Land Economics 65, 342-51.

McMillen, D. P., and J. F. McDonald (1991) "Urban Land Value Functions with Endogenous Zoning." Journal of Urban Economics 29, 14-27.

Miceli, T.J., H.J. Munneke, C. F. Sirmans, and G.K. Turnbull (2002) “Title Systems and Land Values," Journal of Law and Economics, 45, 565-582. 
Miceli, T. J., C. F. Sirmans, and G. K. Turnbull (1998) "Title Assurance and Incentives for Efficient Land Use," European Journal of Law and Economics, 6, 305-323.

Miceli, T. J., C. F. Sirmans, and G. K. Turnbull (2000) “The Dynamic Effects of Land Title Systems," Journal of Urban Economics, 47, 370-389.

Miceli, T. J., C. F. Sirmans, and G. K. Turnbull (2003) "Land Ownership Risk and Urban Development," Journal of Regional Science, 43, 73-54.

Munneke, H. J. (1996) "Redevelopment Decisions for Commercial and Industrial Properties." Journal of Urban Economics 39, 229-253.

Shick, B. and I. Plotkin (1978) Torrens in The United States: A Legal and Economic History and Analysis of American Land Registration Systems, Lexington, Mass: Lexington Books. 
Table 1: Descriptive Statistics - Commercial and Industrial Property Transactions, Cook County, Illinois

\begin{tabular}{|c|c|c|c|c|c|c|c|}
\hline & & $\frac{\text { Full }}{\text { Mean }}$ & $\begin{array}{c}\text { Full } \\
\text { St Dev }\end{array}$ & $\begin{array}{l}\text { Rec. } \\
\text { Mean }\end{array}$ & $\frac{\text { Rec. }}{\text { St Dev }}$ & $\begin{array}{c}\text { Reg. } \\
\text { Mean }\end{array}$ & $\begin{array}{c}\text { Reg. } \\
\text { St Dev }\end{array}$ \\
\hline$U C B D_{i}$ & Distance to central business district (in miles) & 10.5615 & 6.4659 & 10.2183 & 6.3093 & 14.1554 & 6.9876 \\
\hline $\mathrm{CHICAGO}_{i}$ & Property located within Chicago city limits & 0.5683 & 0.4954 & 0.5879 & 0.4923 & 0.3641 & 0.4823 \\
\hline$U O H A R E_{i}$ & Distance to O'Hare (in miles) & 12.3266 & 6.3104 & 12.4176 & 6.2018 & 11.3738 & 7.3010 \\
\hline UOHARE_D $D_{i}$ & 1, if $U O H A R E_{i} \leq 5 ; 0$, else & 0.0880 & 0.2834 & 0.0825 & 0.2752 & 0.1456 & 0.3536 \\
\hline$U R O A D_{i}$ & $\begin{array}{l}\text { Distance to high concentration of roadway activity; } 0 \text {, } \\
\text { else }\end{array}$ & 3.6110 & 2.0837 & 3.6096 & 2.0857 & 3.6257 & 2.0679 \\
\hline$U R O A D \_D_{i}$ & 1, if $U R O A D_{i} \leq 1 ; 0$, else & 0.0724 & 0.2591 & 0.0728 & 0.2598 & 0.0680 & 0.2523 \\
\hline$U R A I L_{i}$ & Distance to high concentration of railway activity; 0 , else & 3.6079 & 2.9905 & 3.5016 & 2.9228 & 4.7219 & 3.4394 \\
\hline$U R A I L \_D_{i}$ & 1, if $U R A I L_{i} \leq 1 ; 0$, else & 0.1468 & 0.3540 & 0.1521 & 0.3592 & 0.0922 & 0.2901 \\
\hline & Distance to high concen & & & & & & \\
\hline$U C O N_{i}$ & space & 2.6323 & 2.0837 & 2.7005 & 2.1200 & 1.9186 & 1.4817 \\
\hline$U C O N \_D_{i}$ & 1, if UOPEN_CON $N_{i} \leq 1 ; 0$, else & 0.2027 & 0.4021 & 0.1943 & 0.3957 & 0.2913 & 0.4555 \\
\hline$U R E C_{i}$ & Dist. to high concentration of open recreational space & 1.1886 & 0.6078 & 1.1753 & 0.6049 & 1.3273 & 0.6218 \\
\hline$U R E C \_D_{i}$ & 1, if UOPEN_REC $C_{i} \leq 1 ; 0$, else & 0.3479 & 0.4764 & 0.3561 & 0.4789 & 0.2621 & 0.4409 \\
\hline$T B A_{i} / 10000$ & Total building area (sq ft/10000) & 1.3486 & 3.4146 & 1.3879 & 3.5251 & 0.9375 & 1.8619 \\
\hline$L O T_{i}$ & Lot area of the parcel (sq. ft.) & 24,237 & 67,237 & 24,067 & 66,716 & 26,025 & 72,614 \\
\hline$A G E_{i}$ & Age of improvement (in yrs) & 43.8917 & 27.3774 & 44.4817 & 27.6524 & 37.7136 & 23.4953 \\
\hline$L U_{-} C O M_{i}$ & 1, if commercial land use; 0 else & 0.6961 & 0.4600 & 0.6973 & 0.4595 & 0.6845 & 0.4659 \\
\hline$L U_{-} I N D_{i}$ & 1, if industrial land use; 0 , else & 0.3039 & 0.4600 & 0.3027 & 0.4595 & 0.3155 & 0.4659 \\
\hline YROS8687i & 1, if property sold in 1986 or 1987; 0, else & 0.4799 & 0.4997 & 0.4840 & 0.4999 & 0.4369 & 0.4972 \\
\hline YROS9091 & 1, if property sold in 1990 or 1991; 0, else & 0.5201 & 0.4997 & 0.5160 & 0.4999 & 0.5631 & 0.4972 \\
\hline$R_{E G R E N S_{i}}$ & 1, if property sold as Registered property; 0, else & 0.0872 & 0.2822 & 0.0000 & 0.0000 & 1.0000 & 0.0000 \\
\hline & 1 , if the number of Registered property within a $m$ & & & & & & \\
\hline$R_{E G C O N}$ & 5, 0 else & 0.5036 & 0.5001 & 0.4780 & 0.4996 & 0.7718 & 0.4207 \\
\hline$C D F_{i}$ & Probability Registered - Cumulative distribution function & 0.0873 & 0.0850 & 0.0787 & 0.0735 & 0.1778 & 0.1322 \\
\hline$S E L E C T_{i}$ & Selection Variable & 0.1391 & 0.0930 & 0.1306 & 0.0875 & 0.2283 & 0.1018 \\
\hline Sample Size & & 2363 & & 2157 & & 206 & \\
\hline
\end{tabular}


Table 2: Estimation Results - Title System Choice Equation*

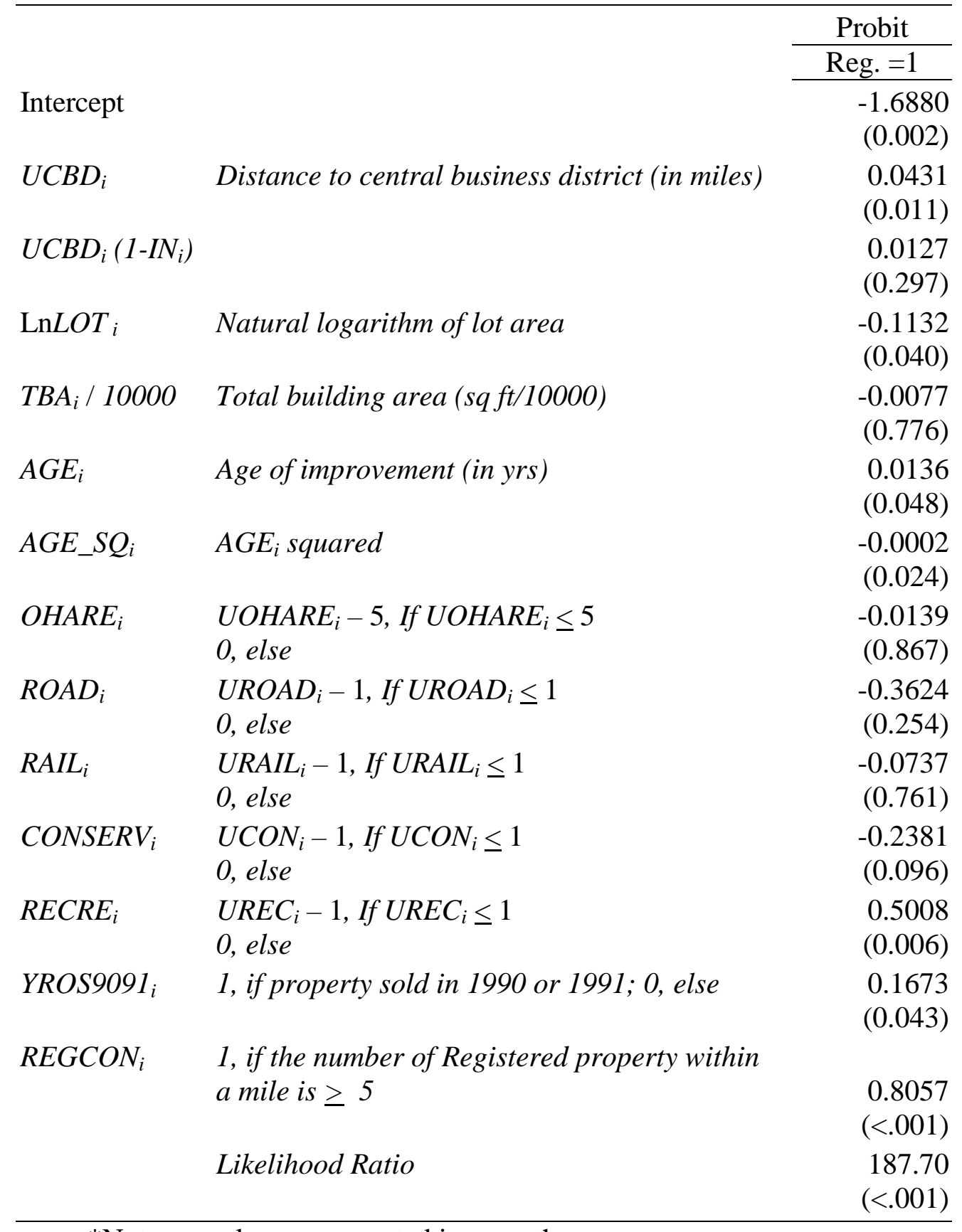

*Note: p-values are reported in parentheses. 
Table 3: Estimation Results -Total Price Equation*

\begin{tabular}{|c|c|c|c|}
\hline & & Com. & Ind. \\
\hline Intercept & & $\begin{array}{l}8.1596 \\
(26.30)\end{array}$ & $\begin{array}{l}8.2971 \\
(23.01)\end{array}$ \\
\hline$U C B D_{i}$ & Distance to central business district (in miles) & $\begin{array}{r}-0.0569 \\
(7.73)\end{array}$ & $\begin{array}{r}-0.0636 \\
(6.09)\end{array}$ \\
\hline$U C B D_{i}\left(1-I N_{i}\right)$ & & $\begin{array}{r}0.0219 \\
(5.23)\end{array}$ & $\begin{array}{r}0.0383 \\
(5.06)\end{array}$ \\
\hline $\ln L O T_{i}$ & Natural logarithm of lot area & $\begin{array}{r}0.5001 \\
(13.99)\end{array}$ & $\begin{array}{r}0.4531 \\
(12.57)\end{array}$ \\
\hline$T B A_{i} / 10000$ & Total building area (sq ft/10000) & $\begin{array}{r}0.0956 \\
(4.46)\end{array}$ & $\begin{array}{r}0.0874 \\
(6.12)\end{array}$ \\
\hline$A G E_{i}$ & Age of improvement (in yrs) & $\begin{array}{r}-0.0133 \\
(4.91)\end{array}$ & $\begin{array}{r}-0.0223 \\
(5.12)\end{array}$ \\
\hline$A G E \_S Q_{i}$ & $A G E_{i}$ squared & $\begin{array}{r}0.0001 \\
(4.15)\end{array}$ & $\begin{array}{r}0.0002 \\
(4.12)\end{array}$ \\
\hline$O H A R E_{i}$ & $\begin{array}{l}\text { UOHARE }_{i}-5, \text { If UOHARE } \\
\text { O, else } \leq 5\end{array}$ & $\begin{array}{r}-0.0946 \\
(2.06)\end{array}$ & $\begin{array}{r}-0.0572 \\
(1.99)\end{array}$ \\
\hline$R O A D_{i}$ & $\begin{array}{l}U R O A D_{i}-1, \text { If } U R O A D_{i} \leq 1 \\
\text {, else }\end{array}$ & $\begin{array}{r}-0.1163 \\
(0.61)\end{array}$ & $\begin{array}{r}-0.0285 \\
(0.19)\end{array}$ \\
\hline$R A I L_{i}$ & $\begin{array}{l}U R A I L_{i}-1, \text { If } U R A I L_{i} \leq 1 \\
0, \text { else }\end{array}$ & $\begin{array}{r}0.8253 \\
(10.29)\end{array}$ & $\begin{array}{r}0.3104 \\
(2.42)\end{array}$ \\
\hline CONSERV $V_{i}$ & $\begin{array}{l}U_{C O N_{i}}-1, \text { If } U C O N_{i} \leq 1 \\
0, \text { else }\end{array}$ & $\begin{array}{r}-0.1191 \\
(2.01)\end{array}$ & $\begin{array}{r}0.0140 \\
(0.17)\end{array}$ \\
\hline$R E C R E_{i}$ & $\begin{array}{l}U R E C_{i}-1, \text { If } U R E C_{i} \leq 1 \\
0, \text { else }\end{array}$ & $\begin{array}{r}-0.3242 \\
(4.89)\end{array}$ & $\begin{array}{r}-0.2034 \\
(1.59)\end{array}$ \\
\hline YROS9091 $i_{i}$ & 1, if property sold in 1990 or 1991; 0, else & $\begin{array}{r}0.1811 \\
(5.95)\end{array}$ & $\begin{array}{r}0.2068 \\
(4.65)\end{array}$ \\
\hline$C D F_{i}$ & Endogenous Registration variable & $\begin{array}{r}2.1204 \\
(3.66)\end{array}$ & $\begin{array}{r}-2.3716 \\
(2.88)\end{array}$ \\
\hline \multirow[t]{2}{*}{ SELECT $_{i}$} & Selection Variable & $\begin{array}{r}-0.9404 \\
(1.80)\end{array}$ & $\begin{array}{r}3.3835 \\
(4.24)\end{array}$ \\
\hline & Adj $R-s q$ & 0.5541 & 0.6281 \\
\hline
\end{tabular}

*Note: The dependent variable is the log of sales price. The Lee, et al. (1980) error adjustment is used to calculate the asymptotic t-statistics reported in parentheses. 


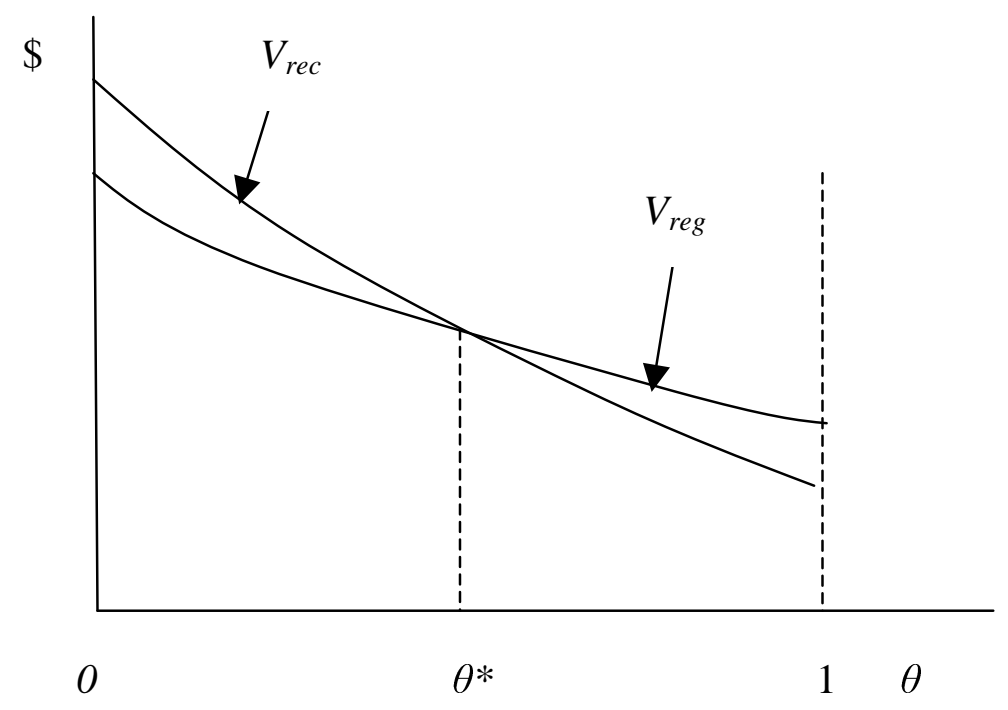

Figure 1. Choice between title systems as a function of title risk. 